\title{
Determinants of the development of post-traumatic stress disorder, in the general population
}

\author{
Marc Perrin • Caroline L. Vandeleur • Enrique Castelao • Stéphane Rothen • \\ Jennifer Glaus $\cdot$ Peter Vollenweider $\cdot$ Martin Preisig
}

Received: 29 April 2013/Accepted: 30 August 2013/Published online: 11 September 2013

(C) Springer-Verlag Berlin Heidelberg 2013

\begin{abstract}
Purpose To assess (1) the lifetime prevalence of exposure both to trauma and post-traumatic stress disorder (PTSD); (2) the risk of PTSD by type of trauma; and (3) the determinants of the development of PTSD in the community. Methods The Diagnostic Interview for Genetic Studies was administered to a random sample of an urban area $(N=3,691)$.

Results (1) The lifetime prevalence estimates of exposure to trauma and PTSD were 21.0 and $5.0 \%$; respectively, with a twice as high prevalence of PTSD in women compared to men despite a similar likelihood of exposure in the two sexes; (2) Sexual abuse was the trauma involving the highest risk of PTSD; (3) The risk of PTSD was most strongly associated with sexual abuse followed by preexisting bipolar disorder, alcohol dependence, antisocial personality, childhood separation anxiety disorder, being victim of crime, witnessing violence, Neuroticism and Problem-focused coping strategies. After adjustment for
\end{abstract}

M. Perrin and C. L. Vandeleur contributed equally to the completion of this paper.

M. Perrin · C. L. Vandeleur $(\square) \cdot$ E. Castelao $\cdot$ S. Rothen ·

J. Glaus · M. Preisig

Department of Psychiatry, Center for Research in Psychiatric Epidemiology and Psychopathology (CEPP), University

Hospital of Lausanne, Site de Cery, 1008 Prilly, Switzerland

e-mail: Caroline.Vandeleur@chuv.ch

\section{S. Rothen · J. Glaus}

Department of Mental Health and Psychiatry, University

Hospital of Geneva, Geneva, Switzerland

P. Vollenweider

Department of Internal Medicine, Lausanne University Hospital, Lausanne, Switzerland these characteristics, female sex was no longer found to be significantly associated with the risk of PTSD.

Conclusions The risk for the development of PTSD after exposure to traumatic events is associated with several factors including the type of exposure, preexisting psychopathology, personality features and coping strategies which independently contribute to the vulnerability to PTSD.

Keywords Post-traumatic stress disorder - Trauma .

Risk factors · Epidemiology

\section{Introduction}

Post-traumatic stress disorder (PTSD) as defined in the DSM-IV is a debilitating psychiatric syndrome with significant social and professional consequences in the affected individual [1]. According to epidemiological surveys in numerous countries, $20-90 \%$ of the general population is exposed to extreme traumatic stressors at least once in their lives (Table 1 [2-20]. The high variance regarding the proportion of exposed individuals is likely to be explained by the application of largely different exposure definitions and the use of samples with different age ranges across studies. However, although a large proportion of the population reported exposure to severe traumatic events according to the majorities of studies, only approximately one-tenth of the exposed individuals subsequently developed PTSD, resulting in lifetime prevalence rates ranging from $1.3 \%$ [6] to $11.2 \%$ [8]. Interestingly, despite generally higher rates of traumatic exposure in men, women consistently revealed a higher lifetime prevalence of PTSD [3-6, 8, 10, 11, 13, 17, 19, 21].

A series of studies have tried to identify exposure-specific and individual factors associated with the risk of 
Table 1 Lifetime prevalence of trauma exposure and PTSD in general population samples including adult subjects

\begin{tabular}{|c|c|c|c|c|c|c|c|c|c|c|c|}
\hline \multirow[t]{2}{*}{ Study } & \multirow[t]{2}{*}{ Sample } & \multirow[t]{2}{*}{ Instruments } & \multirow[t]{2}{*}{$\begin{array}{l}\text { Definition of trauma } \\
\text { exposure }\end{array}$} & \multicolumn{3}{|c|}{$\begin{array}{l}\text { Prevalence of } \\
\text { exposure }\end{array}$} & \multirow[t]{2}{*}{$\mathrm{M}$ vs. $\mathrm{F} \chi_{2}^{2}$} & \multicolumn{3}{|c|}{$\begin{array}{l}\text { Prevalence of } \\
\text { PTSD }\end{array}$} & \multirow[t]{2}{*}{$\mathrm{M}$ vs. $\mathrm{F} \chi_{2}^{2}$} \\
\hline & & & & $\begin{array}{l}\text { Total } \\
(\%)\end{array}$ & $\begin{array}{l}\mathrm{M} \\
(\%)\end{array}$ & $\begin{array}{l}\mathrm{F} \\
(\%)\end{array}$ & & $\begin{array}{l}\text { Total } \\
(\%)\end{array}$ & $\begin{array}{l}M \\
(\%)\end{array}$ & $\begin{array}{l}\mathrm{F} \\
(\%)\end{array}$ & \\
\hline $\begin{array}{l}\text { Breslau et al. } \\
\text { [2] }\end{array}$ & $\begin{array}{l}\text { USA } \\
\text { Age } 21-30 \\
N=1,007\end{array}$ & NIMH-DIS & $\begin{array}{l}\text { Nine types of traumatic } \\
\text { events according to } \\
\text { DSM-III-R }\end{array}$ & 39.1 & 43.0 & 36.7 & $\begin{array}{l}3.7 \\
p=0.0545\end{array}$ & 9.2 & 6.0 & 11.3 & $\begin{array}{l}7.4 \\
p<0.01\end{array}$ \\
\hline $\begin{array}{l}\text { Kessler et al. } \\
\text { [3] }\end{array}$ & $\begin{array}{l}\text { USA } \\
\text { Age } 15-54 \\
N=5,877\end{array}$ & CIDI-DIS & $\begin{array}{l}11 \text { Types of traumatic } \\
\text { events according to } \\
\text { DSM-III-R and a 12th } \\
\text { event defined as "any } \\
\text { other terrible } \\
\text { experience that most } \\
\text { people never go } \\
\text { through" }\end{array}$ & 55.7 & 60.7 & 51.2 & $\begin{array}{l}53.0 \\
p<0.01\end{array}$ & 7.8 & 5.0 & 10.4 & $\begin{array}{l}58.7 \\
p<0.05\end{array}$ \\
\hline $\begin{array}{l}\text { Stein et al. } \\
{[4]}\end{array}$ & $\begin{array}{l}\text { Canada } \\
\text { Age }>18 \\
N=1,002\end{array}$ & $\begin{array}{l}\text { Modified } \\
\text { PTSD } \\
\text { symptom } \\
\text { scale }\end{array}$ & $\begin{array}{l}12 \text { Types of traumatic } \\
\text { events assessed by the } \\
\text { modified PTSD } \\
\text { symptom scale based } \\
\text { on DSM-IV }\end{array}$ & 77.6 & 81.3 & 74.2 & $\begin{array}{l}6.9 \\
p<0.01\end{array}$ & $\begin{array}{l}2.0 \\
(1-\mathrm{mor} \\
\text { preva }\end{array}$ & $\begin{array}{l}1.2 \\
\text { nth } \\
\text { alence) }\end{array}$ & 2.7 & $\begin{array}{l}1.8 \\
p=0.1789\end{array}$ \\
\hline $\begin{array}{l}\text { Breslau et al. } \\
\text { [5] }\end{array}$ & $\begin{array}{l}\text { USA } \\
\text { Age } 18-45 \\
N=2,181\end{array}$ & WHO-CIDI & $\begin{array}{l}19 \text { Types of traumatic } \\
\text { events according to } \\
\text { DSM-IV }\end{array}$ & 89.6 & - & - & - & 9.2 & 6.2 & 13.0 & $\begin{array}{l}28.6 \\
p<0.001\end{array}$ \\
\hline $\begin{array}{l}\text { Perkonigg } \\
\text { et al. [6] }\end{array}$ & $\begin{array}{l}\text { Germany } \\
\text { Age } 14-24 \\
N=3,021\end{array}$ & M-CIDI & $\begin{array}{l}10 \text { Types of traumatic } \\
\text { events according to } \\
\text { DSM-IV. }\end{array}$ & 21.4 & 25.2 & 17.7 & $\begin{array}{l}25.0 \\
p<0.001\end{array}$ & 1.3 & 0.4 & 2.2 & $\begin{array}{l}19.8 \\
p<0.001\end{array}$ \\
\hline $\begin{array}{l}\text { Creamer } \\
\text { et al. [7] }\end{array}$ & $\begin{array}{l}\text { Australia } \\
\text { Age } \geq 18 \\
N=10,641\end{array}$ & CIDI & $\begin{array}{l}\text { Traumatic events } \\
\text { according to DSM- } \\
\text { IV, plus childhood } \\
\text { abuse and neglect, } \\
\text { torture or terrorism } \\
\text { and any other } \\
\text { extremely stressful or } \\
\text { upsetting event }\end{array}$ & 57.4 & 64.5 & 49.5 & $\begin{array}{l}238.9 \\
p<0.05\end{array}$ & $\begin{array}{l}1.3 \\
(12-\mathrm{mc} \\
\text { preve }\end{array}$ & $\begin{array}{l}1.2 \\
\text { onth } \\
\text { alence) }\end{array}$ & 1.4 & $\begin{array}{l}0.7 \\
p=0.4006\end{array}$ \\
\hline $\begin{array}{l}\text { Norris et al. } \\
{[8]}\end{array}$ & $\begin{array}{l}\text { Mexico } \\
\text { Age } 18-92 \\
N=2,509\end{array}$ & CIDI & $\begin{array}{l}\text { Traumatic events } \\
\text { assessed by the CIDI } \\
\text { (version 2.1) based on } \\
\text { DSM-IV }\end{array}$ & 76.0 & 83.0 & 71.0 & $\begin{array}{l}46.2 \\
p<0.001\end{array}$ & 11.2 & 7.2 & 14.5 & $\begin{array}{l}29.0 \\
p<0.001\end{array}$ \\
\hline $\begin{array}{l}\text { Breslau et al. } \\
\text { [9] }\end{array}$ & $\begin{array}{l}\text { USA } \\
\text { Age } 20-22 \\
N=1,698\end{array}$ & WHO-CIDI & $\begin{array}{l}18 \text { Traumatic events } \\
\text { according to DSM-IV }\end{array}$ & 82.5 & 87.2 & 78.4 & $\begin{array}{l}7.0 \\
p<0.001\end{array}$ & 7.1 & 6.3 & 7.9 & $\begin{array}{l}1.1 \\
p=0.2870\end{array}$ \\
\hline $\begin{array}{l}\text { Frans et al. } \\
{[10]}\end{array}$ & $\begin{array}{l}\text { Sweden } \\
\text { Age } 18-70 \\
N=1,824\end{array}$ & PCL & $\begin{array}{l}\text { Seven traumatic events } \\
\text { assessed by the PTSD } \\
\text { Checklist (based on } \\
\text { DSM-IV) }\end{array}$ & 80.8 & 84.8 & 77.1 & $\begin{array}{l}16.9 \\
p<0.001\end{array}$ & 5.6 & 3.6 & 7.4 & $\begin{array}{l}11.7 \\
p<0.001\end{array}$ \\
\hline $\begin{array}{l}\text { Hapke et al. } \\
\text { [11] }\end{array}$ & $\begin{array}{l}\text { Germany } \\
\text { Age } 18-64 \\
N=4,075\end{array}$ & M-CIDI & $\begin{array}{l}\text { Nine traumatic events } \\
\text { assessed by the } \\
\text { M-CIDI (based on } \\
\text { DSM-IV) }\end{array}$ & 19.8 & 19.5 & 20.0 & $\begin{array}{l}0.1 \\
p=0.7677\end{array}$ & 1.4 & 0.6 & 2.2 & $\begin{array}{l}17.8 \\
p<0.001\end{array}$ \\
\hline $\begin{array}{l}\text { Hepp et al. } \\
\text { [12] }\end{array}$ & $\begin{array}{l}\text { Switzerland } \\
\text { Age } 40 / 41 \\
N=367\end{array}$ & SPIKE & $\begin{array}{l}\text { Four categories of } \\
\text { traumatic events } \\
\text { according to DSM-IV }\end{array}$ & 28 & 27.5 & 28.5 & $\begin{array}{l}0.0 \\
p=1.0\end{array}$ & $\begin{array}{l}0.0 \\
(12-\mathrm{mc} \\
\text { preve }\end{array}$ & $\begin{array}{l}0.0 \\
\text { onth } \\
\text { alence) }\end{array}$ & 0.0 & - \\
\hline $\begin{array}{l}\text { Zlotnick } \\
\text { et al. [13] }\end{array}$ & $\begin{array}{l}\text { Chile } \\
\text { Age } 15-64 \\
N=2,390\end{array}$ & DIS-III-R & $\begin{array}{l}11 \text { Categories of } \\
\text { traumatic events } \\
\text { according to DSM- } \\
\text { III-R. }\end{array}$ & 39.7 & 46.7 & 33.2 & $\begin{array}{l}49.2 \\
p<0.001\end{array}$ & 4.4 & 2.5 & 6.2 & $\begin{array}{l}20.1 \\
p<0.001\end{array}$ \\
\hline
\end{tabular}


Table 1 continued

\begin{tabular}{|c|c|c|c|c|c|c|c|c|c|c|c|}
\hline \multirow[t]{2}{*}{ Study } & \multirow[t]{2}{*}{ Sample } & \multirow[t]{2}{*}{ Instruments } & \multirow[t]{2}{*}{$\begin{array}{l}\text { Definition of trauma } \\
\text { exposure }\end{array}$} & \multicolumn{3}{|c|}{$\begin{array}{l}\text { Prevalence of } \\
\text { exposure }\end{array}$} & \multirow[t]{2}{*}{$\mathrm{M}$ vs. $\mathrm{F} \chi_{2}^{2}$} & \multicolumn{3}{|c|}{$\begin{array}{l}\text { Prevalence of } \\
\text { PTSD }\end{array}$} & \multirow[t]{2}{*}{$\mathrm{M}$ vs. $\mathrm{F} \chi_{2}^{2}$} \\
\hline & & & & $\begin{array}{l}\text { Total } \\
(\%)\end{array}$ & $\begin{array}{l}\mathrm{M} \\
(\%)\end{array}$ & $\begin{array}{l}\mathrm{F} \\
(\%)\end{array}$ & & $\begin{array}{l}\text { Total } \\
(\%)\end{array}$ & $\begin{array}{l}\mathrm{M} \\
(\%\end{array}$ & $\begin{array}{l}\mathrm{F} \\
(\%)\end{array}$ & \\
\hline $\begin{array}{l}\text { Jeon et al. } \\
\text { [14] }\end{array}$ & $\begin{array}{l}\text { Korea } \\
\text { Age } 18-64 \\
N=6,258\end{array}$ & CIDI & $\begin{array}{l}11 \text { Categories of } \\
\text { traumatic events } \\
\text { according to DSM-IV }\end{array}$ & 33.3 & - & - & - & 1.7 & - & - & - \\
\hline $\begin{array}{l}\text { Maercker } \\
\text { et al. [15] }\end{array}$ & $\begin{array}{l}\text { Switzerland } \\
\text { Age } 65 / 96 \\
N=570\end{array}$ & M-CIDI & $\begin{array}{l}10 \text { Traumatic events } \\
\text { according to DSM-IV } \\
\text { plus an open-ended } \\
\text { question about any } \\
\text { other traumatic events }\end{array}$ & 36.3 & - & - & - & 0.7 & 0.4 & 0.9 & $\begin{array}{l}0.04 \\
p=0.8498\end{array}$ \\
\hline $\begin{array}{l}\text { Van } \\
\text { Ameringen } \\
\text { et al. [16] }\end{array}$ & $\begin{array}{l}\text { Canada } \\
\text { Age } \geq 18 \\
N=2,991\end{array}$ & $\begin{array}{l}\text { Canadian } \\
\text { Community } \\
\text { Health } \\
\text { Survey }\end{array}$ & $\begin{array}{l}18 \text { Types of traumatic } \\
\text { events according to } \\
\text { DSM-IV }\end{array}$ & 75.9 & 78.5 & 73.4 & $\begin{array}{l}9.8 \\
p<0.002\end{array}$ & 9.2 & 5.3 & 12.8 & $\begin{array}{l}43.6 \\
p<0.001\end{array}$ \\
\hline $\begin{array}{l}\text { De Vries and } \\
\text { Olff [17] }\end{array}$ & $\begin{array}{l}\text { Netherlands } \\
\text { Age } 18-80 \\
N=1,087\end{array}$ & CIDI & $\begin{array}{l}36 \text { Specific traumatic } \\
\text { events assessed by the } \\
\text { CIDI and the list of } \\
\text { traumatic events } \\
\text { (Carlier et al. [18]) } \\
\text { based on DSM-IV }\end{array}$ & 80.7 & 80.7 & 80.8 & $\begin{array}{l}0.0 \\
p=0.9982\end{array}$ & 7.4 & 4.3 & 8.8 & $\begin{array}{l}7.3 \\
p<0.01\end{array}$ \\
\hline $\begin{array}{l}\text { Amstadter } \\
\text { et al. [19] }\end{array}$ & $\begin{array}{l}\text { Norway } \\
\text { Age } 19-36 \\
N=2,794\end{array}$ & M-CIDI & $\begin{array}{l}\text { Eight specific traumatic } \\
\text { events according to } \\
\text { DSM-IV, happening } \\
\text { to self- or witnessed } \\
\text { happening to others }\end{array}$ & 26.5 & 31.9 & 23.4 & $\begin{array}{l}23.5 \\
p<0.001\end{array}$ & 9.8 & 3.7 & 14.5 & $\begin{array}{l}11.5 \\
p<0.01\end{array}$ \\
\hline $\begin{array}{l}\text { Lubaschek } \\
\text { et al. [20] }\end{array}$ & $\begin{array}{l}\text { Germany } \\
\text { Age } 25-74 \\
N=3,080\end{array}$ & $\begin{array}{l}\text { Impact of } \\
\text { Event Scale }\end{array}$ & $\begin{array}{l}11 \text { Extremely stressful } \\
\text { events according to } \\
\text { the Post-traumatic } \\
\text { Diagnostic Scale } \\
\text { (ICD-10) }\end{array}$ & 41 & 41.5 & 39.5 & $\begin{array}{l}1.4 \\
p=0.2439\end{array}$ & 1.7 & 1.3 & 2.0 & $\begin{array}{l}2.1 \\
p=0.1491\end{array}$ \\
\hline
\end{tabular}

Limited to studies in which prevalence estimates for exposure both to any traumatic event and PTSD were reported

$M$ males, $F$ females, $\chi_{2}^{2}$ Chi-square $d f(2), N I M H$-DIS The National Institute of Mental Health Diagnostic Interview Schedule, CIDI Composite International Diagnostic Interview, DIS-III-R Diagnostic Interview Schedule III Revised, WHO-CIDI The World Health Organization Composite International Diagnostic Interview, M-CIDI Munich-Composite International Diagnostic Interview, WMH-CIDI The World Mental Health Composite International Diagnostic Interview, SPIKE Structured Psychopathological Interview and rating of the social consequences for epidemiology

developing PTSD after traumatic exposure. These studies $[20,22-24]$ have shown that the type of exposure was strongly associated with the risk of subsequent PTSD. Assaultive violence was the exposure with one of the highest risks of developing PTSD [5, 10, 11, 20]. Moreover, the NCS study has documented that, except for rape, which was the trauma with the highest risk of PTSD in either sex, exposure to combat and witnessing someone being injured or killed was more commonly associated with PTSD in males, whereas sexual molestation was more frequently associated with PTSD in females [3].

Several studies have assessed individual vulnerability factors for the development of PTSD including personality features, coping style, preceding mental disorders and a family history of PTSD or other mental disorders. Five studies observed elevated Neuroticism to be significantly associated with PTSD [2, 25-28]. Regarding preceding psychopathology, three studies have shown that mood [6, 29] or anxiety disorders [6, 11, 29] were significantly associated with the risk of PTSD. Bromet et al. [29] found mood disorders to predict PTSD in women and anxiety disorders to predict PTSD in men. Regarding the family history of psychopathology, two studies documented associations between a positive family history of anxiety disorders [30] or PTSD and the risk of developing PTSD in both sexes [31]. In contrast, Dierker and Merikangas [32] did not find a family history of PTSD to be associated with the risk of PTSD.

The higher risk of PTSD after exposure to traumatic events in women is still poorly understood [24]. Beside reporting bias, it has been hypothesized that the greater vulnerability of women to develop PTSD could be 
attributable to the sex-specific distribution differences of traumatic exposures, the tendency of women to exhibit higher levels of Neuroticism and anxiety [24] or gender differences in coping style [33].

Up to date, most studies have focused on a very limited number of potential risk factors for the development of PTSD, which mostly included socio-demographic characteristics and the type of traumatic exposure. This impeded the studies to assess the specific effect of one risk factor with adjustment for the effects of the others, and therefore limited the insight into the mechanisms involved in the development of PTSD in exposed individuals.

\section{Aims of the study}

Using a population-based sample, the aims of the present paper were to determine: (1) the lifetime prevalence of exposure both to traumatic events and PTSD, and (2) simultaneously assess the effects of a large array of factors potentially involved in the development of PTSD including socio-demographic characteristics, the specific type of exposure, preexisting psychiatric disorders, family history of disorders, personality features and coping style.

\section{Materials and methods}

Sample

The data of the present paper stemmed from the population-based PsyCoLaus study. Initially, a sample of 6,734 subjects (CoLaus study) was recruited in the general population of Lausanne (Switzerland) to assess the prevalence of cardiovascular risk factors (CVRF) and diseases (CVD). The random selection of participants was based on a complete list of the inhabitants of Lausanne aged 35-75 years in 2003, provided by the population registry of the city [34]. Letters of invitation were sent to citizens in the age range of 35-75 years because the incidence of somatic CVRF predisposing to CVD is frequently situated within this age range. A second letter of invitation was sent if there was no response to the first one, after which phone calls were made to try and improve participation rates. The only exclusion criterion for the study was refusal to participate. After study participation, all the subjects were informed of the results of their somatic exam and received compensation for travel costs. Sixty-seven percent of the participants of the CoLaus study in the age range of 35-66 years $(N=5,535)$ also agreed to take part in the psychiatric evaluation (PsyCoLaus), which resulted in a sample of 3,717 individuals who underwent both the somatic/cardiovascular and psychiatric examinations [35].
The upper age bound of the PsyCoLaus sample was set to 66 years to exclude subjects with an inaccurate psychiatric assessment (due to increased rates of people with cognitive impairment and Alzheimer disease or an increased risk of depression due to advanced CVD). Participants received information on their psychiatric status if they so requested and again received compensation for travel costs. The mean age was 50.9 years (SD 8.8 years), $52.9 \%$ were women and the mean socio-economic status (SES) was 3.4 (SD 1.2) according to the Hollingshead scale [36]. Ninetytwo percent of the samples were Caucasians. The gender distribution of the PsyCoLaus sample did not differ significantly from that of the general population in the same age range [35]. Although the youngest 5-year band of the cohort was underrepresented and the oldest 5-year band overrepresented, participants of PsyCoLaus and individuals who refused to participate had comparable scores on the General Health Questionnaire (GHQ-12) [37] (French translation) [38], a self-rating instrument which assessed psychiatric symptoms at the physical examination. In the present paper, 26 subjects were excluded because of missing data on PTSD exposure.

The CoLaus and subsequently the PsyCoLaus study were approved by the institutional review board and subjects gave written informed consent for their participation after having received a detailed description of the goal and funding of the study.

\section{Assessments}

Diagnostic information was collected using the semistructured Diagnostic Interview for Genetic Studies (DIGS $[39,40])$. The DIGS was developed by the NIMH Molecular Genetics Initiative to obtain a more precise assessment of phenotypes through a wide spectrum of DSM-IV Axis-I criteria. The DIGS was completed with the PTSD and the generalized anxiety disorder (GAD) sections of the French version [41] of the Schedule for Affective Disorders and Schizophrenia-lifetime and anxiety disorder version (SADS-LA) [42], and the brief phobia chapter of the DIGS was replaced by the corresponding more extensive chapters of the SADS-LA which elicited detailed information relating to the DSM-IV criteria for agoraphobia with or without panic attacks, social and specific phobias. The presence of PTSD, bipolar disorders, anxiety disorders (GAD, social phobia, agoraphobia with or without panic disorder), alcohol dependence, illicit drug use (marijuana, narcotic or cocaine dependence) and separation anxiety disorder was established if DSM-IV criteria were met using each relevant section of the diagnostic interview. Each section comprised a question regarding the age of onset of the disorder which allowed determining whether the disorder preceded or followed the onset of PTSD. The PTSD 
section of the SADS-LA also assesses exposure to the following four types of traumatic events: (1) accident or severe catastrophe, (2) violent crime, (3) active combat or war, and (4) witnessing trauma to others. Exposure to sexual trauma including rape, sexual abuse and exhibitionism was evaluated within the question on exposure to violent crime and coded separately. The presence of PTSD symptoms was associated with the specific type of exposure. If more than one type of exposure was documented, the interviewer determined which type had led to the development of PTSD symptoms. Age related to the traumatic event associated with PTSD symptoms was also recorded.

The French version of the DIGS [43, 44] as well as the anxiety sections of the SADS-LA [41] revealed excellent inter-rater and fair to good test-retest reliability for mood, substance use and anxiety disorders. As the PTSD section of the French version of the SADS-LA had not been validated before, we tested the 3-year test-retest reliability in terms of Yule's Y coefficients for this diagnosis as well as for exposure to specific traumatic events in 176 psychiatric patients. Despite the very long test-retest interval, the Yule's Y coefficients for the diagnosis of PTSD as well as for exposure to violent crime and sexual trauma were as high as $0.69,0.84$ and 0.57 , respectively. In contrast, the Yule's Y coefficients for exposure to accidents and witnessing trauma to others were low $(0.30$ and 0.22 , respectively), and the test-retest reliability for exposure to war could not be tested given its rareness in this sample. Interviewers were required to be masters-level psychologists and were trained over a 2-month period. Each interview was reviewed by an experienced senior clinical psychologist.

Family history information on PTSD, mood (bipolar or unipolar disorders) and anxiety (GAD, social phobia, agoraphobia with or without panic) disorders was collected using the Family History-Research Diagnostic Criteria (FH-RDC) [45]. Similar to the diagnoses established using the DIGS, the presence of each type of disorder was determined using DSM-IV criteria. The validity of the French version of the FH-RDC has previously been established through the assessment of agreement between diagnoses relying on family history reports and direct interviews for a series of diagnoses in adults [46] [47] and children [48].

Neuroticism was assessed by the Eysenck Personality Questionnaire (EPQ) [49]. The French version of the instrument was validated by its originators [50]. Using three different French samples, the authors reported Cronbach's alpha coefficients ranging from 0.78 to 0.87 for Neuroticism.

Coping strategies were assessed using the French version [51] of the coping section of the Euronet questionnaire
[52]. According to its originators, this self-rating instrument, which contains 17 four-level likert items, measures the two coping dimensions: Active problem resolution strategy and Emotional problem resolution [52]. As no data on the validity of the French version were available, we conducted a principal component analysis in the participants of PsyCoLaus $(N=2,308)$, which suggested a 3 -factor rather than a 2-factor solution. The three factors included the dimensions of Emotion-focused coping (9 items), Help-seeking (4 items) and Problem-focused coping (4 items). A confirmatory factor analysis based on an unweighted least squares (ULS) procedure in the adult relatives $(N=719)$ of the participants of PsyCoLaus revealed a satisfactory fit of this 3-factor solution with a Parsimonious Goodness-of-Fit Index (PGFI) of 0.80 [53] and a standardized root mean-square residual (SRMSR) of 0.07 [54]. The standardized Cronbach's alpha coefficients for the dimensions of Emotion-focused coping, Helpseeking and Problem-focused coping were 0.65, 0.69 and 0.44, respectively. As the Emotion-focused coping dimension of the Euronet questionnaire was highly correlated with EPQ_Neuroticism $(r=0.63 ; p<0001)$ - we did not include this dimension in the logistic regression models.

\section{Statistical analysis}

Bivariate associations between the type of exposure and PTSD were assessed using Chi-square tests. Associations between PTSD and potential determinants of PTSD among exposed subjects were established using logistic regression models, which included the PTSD status as the dependent variable and the potential risk factors for PTSD as independent variables. The models were adjusted for the effects of age, sex, the socio-economic level and the age of exposure to trauma. In model 1, we only included the specific type of exposure to trauma. In model 2, we further introduced preexisting psychiatric disorders (mood and anxiety disorders, alcohol and illicit drug dependence and early separation anxiety disorder if the onset was earlier than the exposure to the first traumatic event) and the family history of mood and anxiety disorders as well as of PTSD. Finally, in model 3, we further included personality features (Neuroticism, antisocial personality) and coping strategies. As previous studies suggested higher vulnerability of women to PTSD, we also tested interactions between sex and the potential risk factors regarding the development of PTSD. Given the high number of interactions tested, the significance level for interaction terms was set to $p<0.01$.

Statistical analyses were performed using the Statistical Analysis System, version 9.2 (SAS Institute, Inc., Cary, NC, USA). 
Table 2 Lifetime prevalence of exposure to traumatic events and lifetime and 12-month prevalence of PTSD for the overall sample and by sex

\begin{tabular}{|c|c|c|c|c|c|}
\hline & \multirow{2}{*}{$\begin{array}{l}\text { Total \% }(95 \% \mathrm{CI}) \\
(N=3,691)\end{array}$} & \multirow{2}{*}{$\begin{array}{l}\text { Females \% }(95 \% \mathrm{CI}) \\
(N=1,956)\end{array}$} & \multirow{2}{*}{$\begin{array}{l}\text { Males \% }(95 \% \mathrm{CI}) \\
(N=1,735)\end{array}$} & \multicolumn{2}{|c|}{ Females vs. males } \\
\hline & & & & $\chi^{2}$ & $p$ \\
\hline \multicolumn{6}{|c|}{ Type of trauma exposure } \\
\hline Sexual abuse & $3.1(2.6-3.7)$ & $5.1(4.1-6.0)$ & $0.9(0.5-1.4)$ & 52.2 & $<0.001$ \\
\hline Crime & $4.1(3.4-4.7)$ & $5.3(4.3-6.3)$ & $2.7(1.9-3.5)$ & 15.4 & $<0.001$ \\
\hline War & $2.1(1.6-2.5)$ & $1.2(0.7-1.7)$ & $3.1(2.2-3.9)$ & 15.0 & $<0.001$ \\
\hline Witnessing violence & $10.5(9.5-11.5)$ & $8.7(7.5-10.0)$ & $12.5(10.9-14.1)$ & 13.9 & $<0.001$ \\
\hline Accident & $5.6(4.9-6.4)$ & $5.0(4.0-6.0)$ & $6.3(5.2-7.5)$ & 3.1 & 0.0804 \\
\hline Any trauma & $21.0(20.0-22.3)$ & $21.7(19.8-23.5)$ & $20.2(18.3-22.1)$ & 1.2 & 0.2816 \\
\hline \multicolumn{6}{|l|}{ PTSD } \\
\hline Lifetime & $5.0(4.3-5.7)$ & $6.5(5.4-7.6)$ & $3.2(2.4-4.1)$ & 21.3 & $<0.001$ \\
\hline 12-month & $1.1(0.7-0.1)$ & $1.4(0.9-1.9)$ & $0.7(0.3-1.2)$ & 3.4 & 0.0646 \\
\hline
\end{tabular}

Some subjects had more than one type of traumatic exposure

$95 \%$ CI $95 \%$ confidence intervals

Table 3 Lifetime risk of PTSD by type of traumatic exposure among exposed subjects

\begin{tabular}{|c|c|c|c|c|c|c|c|c|}
\hline \multirow[t]{2}{*}{$\begin{array}{l}\text { Type of } \\
\text { exposure }\end{array}$} & \multicolumn{2}{|c|}{ Total $(N=775)$} & \multicolumn{2}{|c|}{ Females $(N=424)$} & \multicolumn{2}{|c|}{ Males $(N=351)$} & \multicolumn{2}{|c|}{$\begin{array}{l}\text { Females vs. } \\
\text { Males }\end{array}$} \\
\hline & $N$ exposed & $\begin{array}{l}\text { Risk of PTSD \% } \\
(95 \% \mathrm{CI})\end{array}$ & $N$ exposed & $\begin{array}{l}\text { Risk of PTSD \% } \\
(95 \% \mathrm{CI})\end{array}$ & $N$ exposed & $\begin{array}{l}\text { Risk of PTSD \% } \\
(95 \% \mathrm{CI})\end{array}$ & $\chi^{2}$ & $p$ \\
\hline Sexual abuse & 110 & $47.3(37.8-56.8)$ & 95 & $48.4(38.2-58.7)$ & 15 & $40.0(11.9-68.1)$ & 0.4 & 0.5438 \\
\hline Crime & 120 & $27.5(19.4-35.6)$ & 83 & $30.1(20.0-40.2)$ & 37 & $21.6(7.7-35.5)$ & 0.9 & 0.3356 \\
\hline War & 57 & $12.3(3.4-21.1)$ & 20 & $5.0(-0.55$ to 15.5$)$ & 37 & $16.2(3.8-28.7)$ & 1.5 & 0.2182 \\
\hline Witnessing violence & 328 & $20.1(15.8-24.5)$ & 145 & $26.2(19.0-33.5)$ & 183 & $15.3(10.0-20.6)$ & 5.8 & $<0.05$ \\
\hline Accident & 160 & $16.3(10.5-22.0)$ & 83 & $21.7(12.6-30.7)$ & 77 & $10.4(3.4-17.4)$ & 3.8 & 0.0529 \\
\hline Any trauma & 775 & $23.7(20.7-26.7)$ & 424 & $30.2(25.8-34.6)$ & 351 & $16.0(12.1-19.8)$ & 21.5 & $<0.001$ \\
\hline
\end{tabular}

According to the traumatic event which was associated with the development of PTSD

$95 \%$ CI $95 \%$ confidence intervals

\section{Results}

Lifetime prevalence of exposure to traumatic events and lifetime and 12-month prevalence of PTSD

The lifetime and 12-month prevalence for PTSD as well as the rates of lifetime exposure to traumatic events are presented in Table 2 for the overall sample as well as by sex. Almost one quarter of subjects reported exposure to any type of trauma, with no significant difference between females and males. However, females were more frequently exposed to sexual abuse or crime than males, whereas males reported exposure to traumatic events in war or having witnessed violence more frequently than females.

From the total sample of 3,691 subjects, $184(5.0 \%)$ met criteria for a DSM-IV lifetime diagnosis of PTSD. Although women were not at a greater risk of exposure to any traumatic event than men, they were twice as likely to meet lifetime criteria for PTSD as men. The 12-month prevalence estimate of PTSD was also higher in women than in men, but the difference did not reach the threshold of statistical significance.

Lifetime risk of PTSD by type of traumatic exposure

Among the 775 subjects who had been exposed to at least one traumatic event, approximately a quarter developed PTSD during lifetime (Table 3). The likelihood to develop PTSD after any exposure was twice as high in women as in men. Among the specific types of traumatic exposure, sexual abuse led to PTSD most frequently, followed by exposure to crime, witnessing violence, accidents and war. Except for witnessing violence, which was more strongly associated with PTSD in females than in males, the probability of developing PTSD after a specific type of exposure did not vary by sex. 
Risk factors for the lifetime development of PTSD

Table 4 reveals the levels of demographic variables, types of exposure, preexisting psychiatric disorders and family history as well as personality features and coping strategies by the lifetime presence of PTSD in the sample of exposed subjects. For these analyses, the sample was restricted to subjects with completed self-rating instruments (including Neuroticism and coping strategy scores). Table 4 also provides the results of the three logistic regression models of increasing complexity. Model 1 included socio-demographic characteristics as well as the age and types of exposure to traumatic events. The model did not reveal significant interactions between sex and specific types of exposure according to the pre-defined criteria. Accordingly, we only present the results of the model including the main effects of the tested variables in the whole sample. This model revealed that the lifetime risk of developing PTSD was higher after sexual trauma, exposure to crime and witnessing violence than after accidents. The highest risk was observed after sexual abuse. Exposure to war was not associated with the risk of developing PTSD. Female sex remained associated with the risk of PTSD in model 1. In model 2, preexisting psychiatric disorders and a family history of mood disorders, anxiety disorders and PTSD were added. In addition to the significant associations between the types of exposure and PTSD resulting from model 1 which were all confirmed, preexisting MDD,

Table 4 Factors associated with the lifetime development of PTSD among exposed subjects $(N=538)$

\begin{tabular}{|c|c|c|c|c|c|c|c|c|}
\hline & \multirow{2}{*}{$\begin{array}{l}\text { PTSD } \\
(\%, \text { mean })\end{array}$} & \multirow{2}{*}{$\begin{array}{l}\text { No PTSD } \\
(\%, \text { mean })\end{array}$} & \multicolumn{2}{|l|}{ Model 1} & \multicolumn{2}{|l|}{ Model 2} & \multicolumn{2}{|l|}{ Model 3} \\
\hline & & & OR & $95 \% \mathrm{CI}$ & OR & $95 \% \mathrm{CI}$ & OR & $95 \% \mathrm{CI}$ \\
\hline \multicolumn{9}{|l|}{ Demographic variables } \\
\hline Female sex & 70.0 & 51.7 & $1.8^{*}$ & $1.1-2.9$ & 1.6 & $0.9-2.6$ & 1.7 & $1.0-2.9$ \\
\hline Age & 52.4 & 51.0 & 1.2 & $0.9-1.5$ & $1.3 *$ & $1.0-1.6$ & 1.3 & $1.0-1.6$ \\
\hline Age of exposure & 24.2 & 24.6 & 1.2 & $1.0-1.5$ & 0.9 & $0.7-1.2$ & 0.9 & $0.7-1.2$ \\
\hline Socio-economic level & 3.2 & 3.5 & 0.9 & $0.7-1.0$ & 0.9 & $0.7-1.1$ & 0.9 & $0.7-1.1$ \\
\hline \multicolumn{9}{|l|}{ Type of exposure } \\
\hline Sexual abuse & 30.8 & 7.4 & $10.6 * * *$ & $5.2-21.6$ & $10.8 * * *$ & $5.1-22.7$ & $11.5 * * *$ & $5.3-25.0$ \\
\hline Crime & 23.3 & 18.7 & $2.1^{*}$ & $1.1-3.8$ & $2.5 * *$ & $1.3-4.6$ & $2.8 * *$ & $1.5-5.5$ \\
\hline War & 6.7 & 9.1 & 1.4 & $0.6-3.3$ & 1.3 & $0.5-3.2$ & 1.3 & $0.5-3.4$ \\
\hline Witnessing violence & 48.3 & 50.2 & $2.4 * *$ & $1.4-4.2$ & $2.4 * *$ & $1.4-4.4$ & $2.7 * *$ & $1.5-4.9$ \\
\hline Accident $^{\mathrm{a}}$ & 23.3 & 30.6 & 1.0 & - & 1.0 & - & 1.0 & - \\
\hline \multicolumn{9}{|l|}{ Preexisting disorders } \\
\hline MDD & 24.2 & 14.4 & - & - & $2.3^{*}$ & $1.2-4.3$ & 1.9 & $1.0-3.8$ \\
\hline Bipolar disorders & 3.3 & 0.5 & - & - & $14.9 *$ & $1.8-121.1$ & $11.3 *$ & $1.4-90.9$ \\
\hline Anxiety disorders & 34.2 & 20.6 & - & - & 1.6 & $0.9-2.7$ & 1.5 & $0.9-2.5$ \\
\hline Alcohol dependence & 4.2 & 1.2 & - & - & $6.0^{*}$ & $1.5-24.9$ & $4.9^{*}$ & $1.2-20.8$ \\
\hline Illicit drug use & 1.7 & 1.2 & - & - & 2.4 & $0.4-16.8$ & 1.1 & $0.2-8.5$ \\
\hline Separation anxiety disorder & 12.5 & 3.8 & - & - & $3.5^{* *}$ & $1.5-8.1$ & $3.4 * *$ & $1.4-7.9$ \\
\hline \multicolumn{9}{|l|}{ Family history } \\
\hline Mood disorders & 50.0 & 48.8 & - & - & 0.9 & $0.5-1.4$ & 0.9 & $0.5-1.4$ \\
\hline Anxiety disorders & 22.5 & 19.4 & - & - & 1.6 & $0.6-2.1$ & 1.1 & $0.6-2.0$ \\
\hline PTSD & 12.5 & 9.1 & - & - & 0.9 & $0.4-1.9$ & 0.9 & $0.4-1.9$ \\
\hline \multicolumn{9}{|l|}{ Personality features } \\
\hline Neuroticism score & 12.1 & 9.4 & - & - & - & - & $1.3^{*}$ & $1.0-1.7$ \\
\hline Antisocial personality & 6.7 & 2.6 & - & - & - & - & $4.2 *$ & $1.4-12.7$ \\
\hline \multicolumn{9}{|l|}{ Coping strategies } \\
\hline Problem-focused coping & 8.1 & 7.8 & - & - & - & - & $1.1^{*}$ & $1.0-1.3$ \\
\hline Help-seeking coping & 4.0 & 4.2 & - & - & - & - & 0.9 & $0.8-1.0$ \\
\hline
\end{tabular}

Among exposed subjects with completed self-rating instruments

OR odds ratios, $95 \%$ CI $95 \%$ confidence intervals

$* p<0.05, * * p<0.01, * * * p<0.001$

${ }^{\text {a }}$ Reference group 
bipolar disorder, alcohol dependence and a history of childhood separation anxiety disorder were significantly associated with the development of PTSD, but not a family history of mood disorders, anxiety disorders or PTSD. In model 2, female sex was no longer significantly associated with the risk of PTSD. Finally, model 3 included personality features and coping strategies in addition to the other predictors. Again, this model did not reveal any significant interaction between sex and the type of traumatic exposure, comorbid disorders, family history, personality features or coping strategies. In the final model (without interaction terms), female sex shortly failed to be significantly associated with the risk of developing PTSD. Exposure to sexual abuse revealed the strongest association with the development of PTSD, followed by preexisting bipolar disorder, alcohol dependence, antisocial personality, childhood separation anxiety disorder, being victim of crime, witnessing violence, the level of Neuroticism and Problem-focused coping strategies.

\section{Discussion}

In contrast to previous research, which generally focused on the establishment of prevalence rates and a very limited number of potential risk factors for the development of PTSD, the present population-based study has simultaneously assessed a series of potential risk factors for PTSD including socio-demographic characteristics, the specific type of exposure, preexisting psychiatric disorders, a family history of mood disorders, anxiety disorders or PTSD as well as personality features and coping styles. The simultaneous assessment of these factors allowed us to determine the independent effect of each of them and therefore to gain additional insight into the mechanisms involved in the development of PTSD following traumatic events.

Prevalence of exposure to trauma

Despite considerable methodological differences across studies, our lifetime prevalence of exposure to traumatic events is consistent with those of two studies in Germany $[6,11]$ and a study in Switzerland [12]. Compared to studies conducted in most other European countries or outside of Europe, the lifetime prevalence of exposure to traumatic events established in Germany and Switzerland is relatively low. Given the considerable variety of definitions used for traumatic events, the large differences regarding the prevalence of traumatic events across studies are likely to be attributable to the definition of these events rather than to particularly low exposure rates to such events in Germany and Switzerland. Similarly, our finding of similar overall exposure rates to traumatic events for men and women is in line with the Swiss [12] and all the German studies [6, 11, 20], whereas the majority of previous research documented higher rates in men. However, the observation of strong associations between the type of exposure and sex in our data is consistent with the bulk of existing research, which documented more frequent exposure to sexual abuse $[3,9,10,13,20]$ and crime $[3,17,20]$ in women, but more frequent exposure to war $[3,7,8,10$, $17,20]$ and witnessing of violence in men [3, 6-9]. Nevertheless, given that Hepp et al. [55] documented inconsistencies in the reporting of traumatic events $(63.9 \%)$ across assessments in the longitudinal Zurich study, the possibility of under-reporting events, which may also vary between men and women for different types of exposure (e.g., possible under-reporting of exposure to sexual abuse in men), cannot be ruled out.

Lifetime prevalence of PTSD

Our PTSD lifetime prevalence lay approximately in the middle of the range documented in previous research, but it was higher than that established in the three German studies [6, 11, 20]. Moreover, consistent with most previous studies, we found women to be at least twice as likely to develop PTSD as men [3, 8, 10, 11, 13, 17, 19]. However, with nearly a quarter of exposed individuals developing PTSD, this proportion was considerably higher in our sample than the approximately $10 \%$ observed in most previous studies. The low lifetime prevalence of exposure to traumatic events and the high proneness of exposed individuals to develop PTSD may be attributable to the fact that we have used a relatively stringent definition of traumatic events and thereby identified as exposed-only individuals who were subject to relatively severe traumas.

\section{Risk factors of PTSD in exposed subjects}

A major finding of the present study is the observation that the risk of the development of PTSD after exposure to traumatic events is associated with several factors including the type of exposure, preexisting psychopathology, personality features and coping strategies which all independently contribute to the vulnerability to PTSD. In contrast, we did not find evidence for a potential genetic contribution to the vulnerability to PTSD. Our results show that the risk of PTSD associated with sexual abuse was higher than that associated with other trauma categories, consistent with the results of several other studies [3, 9-11, 13]. Beside the specific type of traumatic event, we also found mental disorders preceding the traumatic event to be associated with the subsequent development of PTSD. This association of bipolar disorder, alcohol dependence and a 
history of separation anxiety disorder with the subsequent risk of PTSD could be attributable to increased vulnerability to traumatic events in subjects already affected with one of these mental disorders. Alternatively, common etiological liability could be involved in both the pathogenesis of these mental disorders and the vulnerability to PTSD following exposure to traumatic events. However, similar to Dierker and Merikangas [32], but unlike Yehuda et al. [31], a positive family history of PTSD was not found to be associated with the risk of PTSD in our study, which does not support a specific major involvement of genetic factors in the vulnerability to PTSD. Regarding personality features, we observed that both antisocial personality disorder and the level of Neuroticism contribute to the vulnerability to PTSD. The finding of increased vulnerability to PTSD in individuals meeting criteria for antisocial personality disorder is rather surprising, whereas the strong association between Neuroticism and the risk of PTSD corroborates the earlier findings of Cox et al. [28]. However, given the cross-sectional nature of existing data, the nature of this association remains unclear. Indeed, either a preexisting high level of Neuroticism could predispose to the development of PTSD after exposure to traumatic events or the occurrence of PTSD could lead to high scores of Neuroticism. Similarly, the high scores of the Problemfocused coping dimension that was found to be associated with the risk of PTSD could be a vulnerability factor for or a consequence of the development of PTSD.

Taken together, these findings suggest a complex interplay of a series of factors that determine the risk of PTSD after traumatic exposure. Stable individual factors including the level of Neuroticism and certain coping styles, which are thought to develop during childhood and adolescence, are likely to increase vulnerability to stressful events [56], but they also predispose to mood or anxiety psychopathology [57], which further increases the vulnerability to stressful events [56]. Although previous research has suggested that genetic factors are involved in the development of personality features [58] as well as in the pathogenesis of mood [59] and anxiety disorders [60], the implication of direct genetic determinants of the vulnerability to PTSD remains controversial, given inconsistent findings regarding the effect of family history on the development of PTSD [31, 32].

Regarding the effect of sex on the risk of developing PTSD, our data confirmed a twice as high risk for women to develop PTSD after exposure to any traumatic event. However, despite the general higher incidence of sexual abuse in women [3, 9-11, 13, 17], this finding does not contribute to explain the higher risk of PTSD in women as we found the risk for PTSD to be similar in men and women among those who were exposed (see also [11]). Similarly, exposure to other types of trauma did not reveal a higher risk of PTSD for females [11], except for witnessing violence where females were again at an almost doubled risk of developing PTSD (see also [13]). Although the variable sex shortly failed to be significantly associated with the risk of developing PTSD after adjustment for other socio-demographic characteristics and potential individual or familial risk factors, a small decrease (from 1.77 to 1.66) of the size of the OR before and after adjustment for these other factors suggests that sex-specific differential distribution of exposure types as well as the increased scores of Neuroticism and the more common history of separation anxiety disorder in women only very partially explain their increased vulnerability to PTSD. Moreover, sex was not found to be a modifier of the effect of the type of exposure or individual or familial characteristics on the vulnerability to PTSD.

\section{Limitations}

The results of the present study should be considered in the context of several limitations. The major limitation is the cross-sectional study design which implies potential recall bias regarding the exposure to traumatic events, the occurrence of mental disorders and the temporal relationship of the onset of these disorders and the traumatic exposure. Also the assessment of both personality traits and coping strategies could have been affected by the presence of PTSD. Only prospective, longitudinal studies can provide measures of potential risk factors before the exposure and therefore they are able to unambiguously establish the sequence of the occurrence of potential risk factors, traumatic events and the development of PTSD. The second limitation is the older age range (35-66 years) of our sample, which reduces the generalizability of our findings and the comparability of our results to those of other similar studies. Third, considering the lower reliability of our coping subscale measuring Problem-focused strategies, the established effect of this coping dimension on the risk of PTSD needs to be considered with caution.

\section{Clinical implications}

Reports of sexual abuse in both males and females require particular attention and, where possible, exposed subjects should benefit from secondary prevention programs directly after such traumatic exposure to hinder the subsequent development of PTSD. Moreover, subjects who were victims of crime and/or who witnessed violence require special clinical attention, and particularly if they present Neurotic personality traits or psychiatric disorders already.

Given the limitations regarding the cross-sectional nature of our data, future studies should follow youth through 
adolescence and early adulthood to provide prospective evidence regarding the complex relationship between early manifestations of psychopathology, personality traits and coping behavior and the risk of developing PTSD following traumatic exposure.

Acknowledgments This research was supported by four grants from the Swiss National Science Foundation (\#32003B-105993, \#32003B-118308, \#33CSC0-122661 and \#139468) and two grants from GlaxoSmithKline Clinical Genetics to G. Waeber, P. Vollenweider and M. Preisig. The authors would like to express their gratitude to the Lausanne inhabitants who volunteered to participate in the PsyCoLaus study.

Conflict of interest On behalf of all authors, the corresponding author states that there is no conflict of interest.

\section{References}

1. Dekkers AMM, Olff M, Näring GWB (2010) Identifying Persons at risk for PTSD After trauma with TSQ in The Netherlands. Community Ment Health J 46:20-25

2. Breslau N, Davis GC, Andreski P, Peterson E (1991) Traumatic events and posttraumatic stress disorder in an urban population of young adults. Arch Gen Psychiatry 48(3):216-222

3. Kessler RC, Sonnega A, Bromet E, Hughes M, Nelson CB (1995) Posttraumatic stress disorder in the National Comorbidity Survey. Arch Gen Psychiatry 52(12):1048-1060

4. Stein MB, Walker JR, Hazen AL, Forde DR (1997) Full and partial posttraumatic stress disorder: findings from a community survey. Am J Psychiatry 154(8):1114-1119

5. Breslau N, Kessler RC, Chilcoat HD, Schultz LR, Davis GC, Andreski P (1998) Trauma and posttraumatic stress disorder in the community: the 1996 Detroit Area Survey of Trauma. Arch Gen Psychiatry 55(7):626-632

6. Perkonigg A, Kessler RC, Storz S, Wittchen HU (2000) Traumatic events and post-traumatic stress disorder in the community: prevalence, risk factors and comorbidity. Acta Psychiatr Scand 101(1):46-59

7. Creamer M, Burgess P, McFarlane AC (2001) Post-traumatic stress disorder: findings from the Australian National Survey of Mental Health and well-being. Psychol Med 31(7):1237-1247

8. Norris FH, Murphy AD, Baker CK, Perilla JL, Rodriguez FG, Rodriguez JJ (2003) Epidemiology of trauma and posttraumatic stress disorder in Mexico. J Abnorm Psychol 112(4):646-656

9. Breslau N, Wilcox HC, Storr CL, Lucia VC, Anthony JC (2004) Trauma exposure and posttraumatic stress disorder: a study of youths in urban America. J Urban Health 81(4):530-544

10. Frans O, Rimmo PA, Aberg L, Fredrikson M (2005) Trauma exposure and post-traumatic stress disorder in the general population. Acta Psychiatr Scand 111(4):291-299

11. Hapke U, Schumann A, Rumpf HJ, John U, Meyer C (2006) Posttraumatic stress disorder: the role of trauma, pre-existing psychiatric disorders, and gender. Eur Arch Psychiatry Clin Neurosci 256(5):299-306

12. Hepp U, Gamma A, Milos G, Eich D, Ajdacic-Gross V, Rossler W, Angst J, Schnyder U (2006) Prevalence of exposure to potentially traumatic events and PTSD. The Zurich Cohort Study. Eur Arch Psychiatry Clin Neurosci 256(3):151-158

13. Zlotnick C, Johnson J, Kohn R, Vicente B, Rioseco P, Saldivia S (2006) Epidemiology of trauma, post-traumatic stress disorder
(PTSD) and co-morbid disorders in Chile. Psychol Med 36(11):1523-1533

14. Jeon HJ, Suh T, Lee HJ, Hahm BJ, Lee JY, Cho SJ, Lee YR, Chang SM, Cho MJ (2007) Partial versus full PTSD in the Korean community: prevalence, duration, correlates, comorbidity, and dysfunctions. Depress Anxiety 24(8):577-585

15. Maercker A, Forstmeier S, Enzler A, Krusi G, Horler E, Maier C, Ehlert U (2008) Adjustment disorders, posttraumatic stress disorder, and depressive disorders in old age: findings from a community survey. Compr Psychiatry 49(2):113-120

16. Van Ameringen M, Mancini C, Patterson B, Boyle MH (2008) Post-traumatic stress disorder in Canada. CNS Neurosci Ther 14:171-181

17. de Vries GJ, Olff M (2009) The lifetime prevalence of traumatic events and posttraumatic stress disorder in the Netherlands. J Trauma Stress 22(4):259-267

18. Carlier IV, Voerman BE, Gersons BP (2000) Intrusive traumatic recollections and comorbid posttraumatic stress disorder in depressed patients. Psychosom Med 62(1):26-32

19. Amstadter AB, Aggen SH, Knudsen GP, Reichborn-Kjennerud T, Kendler KS (2013) Potentially traumatic event exposure, posttraumatic stress disorder, and axis I and II comorbidity in a population-based study of Norwegian young adults. Soc Psychiatry Psychiatr Epidemiol 48(2):215-223

20. Lukaschek K, Kruse J, Emeny RT, Lacruz ME, von Eisenhart Rothe A, Ladwig KH (2013) Lifetime traumatic experiences and their impact on PTSD: a general population study. Soc Psychiatry Psychiatr Epidemiol 48(4):525-532

21. Tolin DF, Foa EB (2006) Sex differences in trauma and posttraumatic stress disorder: a quantitative review of 25 years of research. Psychol Bull 132(6):959-992

22. Brewin CR, Andrews B, Valentine JD (2000) Meta-analysis of risk factors for posttraumatic stress disorder in trauma-exposed adults. J Consult Clin Psychol 68(5):748-766

23. Ozer EJ, Best SR, Lipsey TL, Weiss DS (2003) Predictors of posttraumatic stress disorder and symptoms in adults: a metaanalysis. Psychol Bull 129(1):52-73

24. Breslau N (2009) The epidemiology of trauma, PTSD, and other posttrauma disorders. Trauma Violence Abuse 10(3):198-210

25. McFarlane AC (1988) The aetiology of post-traumatic stress disorders following a natural disaster. Br J Psychiatry 152:116-121

26. Holeva V, Tarrier N (2001) Personality and peritraumatic dissociation in the prediction of PTSD in victims of road traffic accidents. J Psychosom Res 51(5):687-692

27. Fauerbach JA, Lawrence JW, Schmidt CW Jr, Munster AM, Costa PT Jr (2000) Personality predictors of injury-related posttraumatic stress disorder. J Nerv Ment Dis 188(8):510-517

28. Cox BJ, MacPherson PS, Enns MW, McWilliams LA (2004) Neuroticism and self-criticism associated with posttraumatic stress disorder in a nationally representative sample. Behav Res Ther 42(1): 105-114

29. Bromet E, Sonnega A, Kessler RC (1998) Risk factors for DSMIII-R posttraumatic stress disorder: findings from the National Comorbidity Survey. Am J Epidemiol 147(4):353-361

30. Breslau N, Davis GC, Andreski P, Peterson EL, Schultz LR (1997) Sex differences in posttraumatic stress disorder. Arch Gen Psychiatry 54(11):1044-1048

31. Yehuda R, Halligan SL, Bierer LM (2001) Relationship of parental trauma exposure and PTSD to PTSD, depressive and anxiety disorders in offspring. J Psychiatr Res 35(5):261-270

32. Dierker LC, Merikangas KR (2001) Familial psychiatric illness and posttraumatic stress disorder: findings from a family study of substance abuse and anxiety disorders. J Clin Psychiatry 62(9):715-720

33. Peirce JM, Newton TL, Buckley TC, Keane TM (2002) Gender and psychophysiology of PTSD. In: Kimerling R, Ouimette PC, 
Wolfe J (eds) Gender and PTSD. Guilford Press, New York, pp 177-204

34. Firmann M, Mayor V, Vidal PM, Bochud M, Pecoud A, Hayoz D, Paccaud F, Preisig M, Song KS, Yuan X, Danoff TM, Stirnadel HA, Waterworth D, Mooser V, Waeber G, Vollenweider P (2008) The CoLaus study: a population-based study to investigate the epidemiology and genetic determinants of cardiovascular risk factors and metabolic syndrome. BMC Cardiovas Disord 8:6

35. Preisig M, Waeber G, Vollenweider P, Bovet P, Rothen S, Vandeleur C, Guex P, Middleton L, Waterworth D, Mooser V, Tozzi F, Muglia P (2009) The PsyCoLaus study: methodology and characteristics of the sample of a population-based survey on psychiatric disorders and their association with genetic and cardiovascular risk factors. BMC Psychiatry 9:9

36. Hollingshead AB (1975) Four factor index of social status. Yale University Press, New Haven

37. Goldberg DP (1972) The detection of psychiatric illness by questionnaire. Oxford University Press, Oxford

38. Bettshart W, Bolognini M (1996) Questionnaire de santé GHQ-12 (GHQ-12 Health questionnaire). In: Guelfi JB (ed) L'évaluation clinique standardisée en psychiatrie (Standardized clinical evaluation in psychiatry), Tome I (vol 1). Editions Médicales Pierre Fabre, Boulogne

39. Nurnberger JI Jr, Blehar MC, Kaufmann CA, York-Cooler C, Simpson SG, Harkavy-Friedman J, Severe JB, Malaspina D, Reich T (1994) Diagnostic interview for genetic studies. Rationale, unique features, and training. NIMH Genetics Initiative. Arch Gen Psychiatry 51(11):849-859

40. Leboyer M, Barbe B, Gorwood P, Teherani M, Allilaire J, Preisig M, Matthey M, Poyetton V, Ferrero F (1995) Interview diagnostique pour les Etudes Génétiques. INSERM, Paris

41. Leboyer M, Maier W, Teherani M, Lichtermann D, D'Amato T, Franke P, Lepine JP, Minges J, McGuffin P (1991) The reliability of the SADS-LA in a family study setting. Eur Arch Psychiatry Clin Neurosci 241(3):165-169

42. Endicott J, Spitzer RL (1978) A diagnostic interview: the schedule for affective disorders and schizophrenia. Arch Gen Psychiatry 35(7):837-844

43. Preisig M, Fenton BT, Matthey ML, Berney A, Ferrero F (1999) Diagnostic interview for genetic studies (DIGS): inter-rater and test-retest reliability of the French version. Eur Arch Psychiatry Clin Neurosci 249(4):174-179

44. Berney A, Preisig M, Matthey ML, Ferrero F, Fenton BT (2002) Diagnostic interview for genetic studies (DIGS): inter-rater and test-retest reliability of alcohol and drug diagnoses. Drug Alcohol Depend 65(2):149-158

45. Andreasen NC, Endicott J, Spitzer RL, Winokur G (1977) The family history method using diagnostic criteria: reliability and validity. Arch Gen Psychiatry 34:1229-1235

46. Rougemont-Buecking A, Rothen S, Jeanpretre N, Lustenberger Y, Vandeleur CL, Ferrero F, Preisig M (2008) Inter-informant agreement on diagnoses and prevalence estimates of anxiety disorders: direct interview versus family history method. Psychiatry Res 157(1-3):211-223

47. Vandeleur CL, Rothen S, Jeanpretre N, Lustenberger Y, Gamma F, Ayer E, Ferrero F, Fleischmann A, Besson J, Sisbane F, Preisig M (2008) Inter-informant agreement and prevalence estimates for substance use disorders: direct interview versus family history method. Drug Alcohol Depend 92(1-3):9-19

48. Rothen S, Vandeleur CL, Lustenberger Y, Jeanpretre N, Ayer E, Gamma F, Halfon O, Fornerod D, Ferrero F, Preisig M (2009) Parent-child agreement and prevalence estimates of diagnoses in childhood: direct interview versus family history method. Int $\mathrm{J}$ Methods Psychiatr Res 18(2):96-109

49. Eysenck HJ, Eysenck SBG (1975) Manual of the Eysenck Personality Questionnaire. Hodder \& Stoughton Educational, London

50. Eysenck HJ, Eysenck SBG, Gauquelin M, Gauquelin F, Pascal C, Pascal D (1980) The structure of the personality among French compared to that of an English: cross-cultural comparison. La Personnalité 1-2:7-29

51. Bodmer NM, Grob A (1996) Bien-être et contraintes d'adolescents: une comparaison entre adolescents de familles monoparentales et de familles biparentales (well-being and constraints of adolescents: A comparison of adolescents from single-parent and two-parent families). J Int de Psychologie 31(1):39-48

52. Grob A, Bodmer NM, Flammer A (1993) Living conditions in Europe: the case of Switzerland. University of Bern, Institute of Psychology, Bern

53. Mulaik SA, James LR, Van Alstine J, Bennett N (1989) Evaluation of goodness-of-fit indices for structural equation models. Psychol Bull 105:430-445

54. Hu L, Bentler PM (1998) Fit indices in covariance structure modeling: sensitivity to underparameterized model misspecification. Psychol Methods 3(4):424-453

55. Hepp U, Gamma A, Milos G, Eich D, Ajdacic-Gross V, Rossler W, Angst J, Schnyder U (2006) Inconsistency in reporting potentially traumatic events. Br J Psychiatry 188:278-283

56. Garber J (2006) Depression in children and adolescents: linking risk research and prevention. Am J Prev Med 31(6 Suppl 1):S104-S125

57. Garland EL, Fredrickson B, Kring AM, Johnson DP, Meyer PS, Penn DL (2010) Upward spirals of positive emotions counter downward spirals of negativity: insights from the broaden-andbuild theory and affective neuroscience on the treatment of emotion dysfunctions and deficits in psychopathology. Clin Psychol Rev 30(7):849-864

58. Plomin R, Corley R, Caspi A, Fulker DW, DeFries J (1998) Adoption results for self-reported personality: evidence for nonadditive genetic effects? J Pers Soc Psychol 75(1):211-218

59. Merikangas KR, Low NC (2004) The epidemiology of mood disorders. Curr Psychiatry Rep 6(6):411-421

60. Merikangas KR, Low NC (2005) Genetic epidemiology of anxiety disorders. In: Holsboer F, Ströhle A (eds) Anxiety and anxiolytic drugs. Handbook of Experimental Pharmacology, vol 169, pp 163-179 